\title{
Modelling the Dynamic Distribution of Spray Deposits
}

\author{
F. Lebeau ${ }^{1}$ \\ ${ }^{1}$ Unité de Mécanique et Construction, Gembloux Agricultural University, \\ Passage des Déportés, 2, B-5030 Gembloux, Belgium; e-mail of corresponding \\ author: lebeau.f@fsagx.ac.be
}

A mathematical model to estimate the spray distribution of phytopharmaceutical deposits under a spray boom is proposed. It focuses on the need to take account of the dynamic effects of the forward movement of the boom. These are related both to the horizontal and vertical boom movement and to the influence of aerodynamic factors on the nozzle spray distribution.

The distribution of the spray deposits is computed by multiplying the nozzle spray pattern by the time needed to move from one position to the next. Mathematically, this is expressed by a convolution of the trajectory function with the nozzle spray pattern function.

The model is validated through a dynamic test bench aimed at reproducing the boom movements observed in the field. The chosen method to measure the distribution of the spray deposits is a chemical dosage of the sprayed potassium chloride $(\mathrm{KCl})$ solution collected in Petri dishes. A pulse width modulation (PWM) nozzle body fitted on the test bench is used to generate a dynamic distribution of spray deposits from which the dynamic two-dimensional nozzle 
spray pattern is reconstructed. This dynamic nozzle spray pattern introduced in the model allows a far better estimation of the spray deposit distribution to be made than the one obtained using the static nozzle spray pattern which was computed using filtered back-projection.

Keywords: boom movements; spray deposits distribution; spray deposits model.

\section{Introduction}

Chemical spray application remains a crucial step to ensure high yields at low cost in conventional agriculture. However, the increased concern about environmental pollution and the effect of pesticide residues on human health creates a strong demand for more efficient application methods to spray the liquid deposits as uniformly as possible. For a crop sprayer, unwanted vertical and horizontal boom movements of the spray boom are some of the main sources of an irregular spray deposits distribution along with atmospheric parameters. The model presented in this paper relates spray deposition under a nozzle with the spray boom motion. Such a model is useful when the dynamic performance of an existing sprayer is examined as it is needed for a measurement of the sprayer quality regarding to spray application efficiency without time consuming spray deposits measurements. Furthermore, it can be used in combination with virtual prototyping of the boom behaviour based on the equations of motion to evaluate the efficiency of the proposed design on the application process.

The objective of this study is to present and validate a mathematical model to estimate the distribution of spray deposits of phytopharmaceuticals taking account of the dynamic effects of the forward movement of the boom on the spray distribution. 
For comparison purpose, the model based on a dynamic spray pattern is compared with the one based on static spray pattern measurements.

\section{Literature review}

Many authors have developed models for such a purpose. Usually, the basic assumption is that the spray deposits distribution can be computed as a sum of the static spray distribution patterns corresponding to the positions occupied by the nozzles at successive time steps (Nation, 1976; Sinfort, 1991; Ramon \& De Baerdemaeker, 1997; de Jong et al., 2000; Tian \& Zheng, 2000). The static spray pattern is measured under laboratory conditions either on a spray patternator or by weighing the volume collected into a matrix of dishes at fixed time intervals. Eventually, a static spray pattern model is derived from these laboratory measurement that describes, for a specific nozzle, the spray pattern in the horizontal plane according to operating parameters as height, pressure or eventually twist angle (angle between the spray boom and the major axis of the flat fan nozzle spray). The method was found accurate to predict the relative influence of the horizontal and vertical boom movement at very low speed $(\leq 0.3 \mathrm{~m} / \mathrm{s}$ ) (Ramon et al., 1997) but some discrepancies appeared in the prediction of the actual application rate at higher application speed (Lardoux, 2002, de Jong et al., 2000). These last authors comment that the computer model does not take into account the influence of head wind because of the driving speed. Indeed, this may cause the differences between the model and the laboratory results as dynamic spray deposition tests produced an altered bimodal spray pattern differing from the oval shaped static one for TX4 hollow cone nozzles (Smith, 1992). 


\section{Theoretical considerations}

In the chosen co-ordinate system (Fig. 1), the $\mathrm{X}, \mathrm{Y}$ and $\mathrm{Z}$ axes account respectively for the forward, transverse and vertical directions.

The model is based on the assumption that the spray deposits distribution is the result of the time spent by the nozzle at the successive discrete positions (space interval). As the proposed model is based on a constant space interval, it differs from the classical spray deposits modelling approach, that consider a constant time interval. For each space interval, the contribution to the global spray deposits distribution is calculated by the product of the time spent at this position with the two-dimensional spray pattern of the actual nozzle condition such as pressure, height, twist angle. This is represented in Fig. 2 by ellipses of different size and grey levels under each dotted position along the curve describing the trajectory. The contributions at each location are then summed. Mathematically, this is expressed by a convolution of two functions. The first function describes the solicitation applied to the system while the second characterises the system (this function is usually called the impulse response). For the spray application process, the time interval represents the system input while the spray pattern describes the system behaviour.

The time interval spent by a nozzle at the position $(x, y)$ can be expressed by a function $k(x, y)$ in $\mathrm{s} / \mathrm{m}^{2}$. The time interval notion introduced here for a twodimensional trajectory is analogous to the inverse of speed for an one-dimensional trajectory. 
In other respects, under the hypothesis of a stationary distribution of the spray, the spray pattern can be characterised by a function along $x$ and $y$ axis $D(x, y)$ in $\mathrm{ml}^{-\mathrm{m}^{-2}}$.s ${ }^{-1}$ :

The two-dimensional convolution of these two functions results in a twodimensional function $R(x, y)$ in $\mathrm{ml} / \mathrm{m}^{2}$ :

$$
D(x, y) k(x-\xi, y-\psi) \& \psi k=R(x, y)
$$

where $\xi$ is a space shifting variable along the $\mathrm{X}$ axis, $\psi$ is a space shifting variable along the $\mathrm{Y}$ axis and $D(x, y)$ is a function describing the two-dimensional spray pattern distribution.

The implementation of the model implies a knowledge, on one hand, of the twodimensional spray pattern distribution of the nozzle for the operating conditions $D(x, y)$ and, on the other hand, of the input function $k(x, y)$ calculated from the nozzle trajectory. Operating condition modifications that occur during spray process (i.e. height, pressure, spray liquid properties, nozzle twist angle, wind, evaporation) must be taken into account using the pattern characterised for these particular circumstances. Furthermore, the spray pattern must be evaluated for each kind of nozzle or even each nozzle if they present a significant variability.

\section{Materials and methods}

\subsection{Dynamic test bench}


A laboratory test bench (Fig. 3) was designed to measure the dynamical spray deposits distribution of the nozzle in controlled conditions avoiding perturbation by environmental factors. At the upper side, a nozzle was mounted on a small beam (1) that could be moved horizontally along a linear translation table. The linear translation along the forward direction is controlled using a computer, an electronic controller (2) (Compax-s, Parker, Belgium) and a servomotor (HDY92C4-44S1, Parker, Belgium). This system was able to control the speed of the nozzle in the range from $-2 \mathrm{~m} / \mathrm{s}$ to $+2 \mathrm{~m} / \mathrm{s}$. The nozzle was connected to a hydraulic circuitry similar to that used in sprayers with the pressure kept constant by a pressure controller and controlled using a precision digital manometer (0 - 16 bars E813, Bourdon Sedeme, France). Up to five nozzles could be fitted on the spray boom but only one Teejet XR11003VK nozzle (4) was mounted at the centre in the study. Spray collectors (5) were laid on a spray table with adjustable height and slope (6).

The nozzle was mounted in a pulse width modulation (PWM) nozzle body (Fig. 4). The PWM body was a prototype model furnished by Teejet. This technology, initially developed for anti-drift and precision agriculture purposes, offers the possibility to control the opening and closing of the spray nozzle with a very short delay without affecting the spray characteristics (Giles \& Comino, 1990). In our case, it allowed the operation of the opening and closing of the nozzle spray using electronic controls.

A spray solution of potassium chloride, $\mathrm{KCl} 0.7 \mathrm{~g} / \mathrm{l}$ in tap water, was used in the study. Measurements showed that the static spray pattern was not affected by the salt at this concentration. The spray deposits collected in $55 \mathrm{~mm}$ diameter glass Petri dishes were measured using gravimetry. The spray process was repeated to collect sufficient volume (about $5 \mathrm{ml}$ ) in the Petri dishes. Depending on the trial speed, up to 
300 passes were performed on the dynamic test bench to conduct a single measurement, with an automatic control of the opening and closing of the nozzle using the PWM nozzle body. The collected spray was dried to a constant weight at $105^{\circ} \mathrm{C}$ in the drying oven and then measured analytical scales (Ohaus Adventurer AV-65, USA) with $0.1 \mathrm{mg}$ accuracy. The spray deposits were computed from the weight differences of the Petri dishes after and before the trial. This method allowed an accuracy of $1 \%$ together with an reduced time analysis.

\subsection{Nozzle spray pattern}

In this study focusing on the effect of nozzle speed on the spray deposits distribution, a single Teejet XR11003 flat-fan nozzle always mounted with the same twist angle was chosen and the pressure was kept at 2 bar. To model the process correctly, the impulse response must be estimated for the different values taken by these operating parameters.

The static two-dimensional spray pattern was estimated with $2500 \mathrm{~mm}^{2}$ resolution for 300, 500 and $700 \mathrm{~mm}$ heights using filtered-back projection algorithms from onedimensional static spray pattern measurement (Lebeau et al., 2002).

In parallel, a new method was developed to estimate a dynamic spray pattern taking into account the effect of speed which induces ballistic and aerodynamic effects. The two-dimensional dynamic spray pattern is computed from transversal and longitudinal spray deposits distribution measurements, as explained below. The transversal spray deposits distribution was measured at different speeds (from 0,1 to $2 \mathrm{~m} / \mathrm{s}$ ) and heights (30 to $70 \mathrm{~cm}$ ) on the dynamic test bench. Figure 5 illustrates the transverse spray 
deposits distribution at $50 \mathrm{~cm}$ height for the different speeds. The shape of the distribution is affected by the speed increase. The spray pattern observed at low speeds evolves progressively toward a marked bimodal distribution. This is mainly caused by an aerodynamic effect on the smallest droplets. As a matter of fact, the central part of the spray pattern of the flat fan nozzle is mainly formed from small droplets, while the outer part contains more coarse drops (Lund \& Matzen, 1996). This property is confirmed by measurements performed with a Phase Doppler Particle Analyser. Figure 6 shows that the diameter for $10\left(D_{0.1}\right), 50\left(D_{0.5}\right.$ or $V M D$, volume median diameter) and $90\left(D_{0.9}\right)$ per cent of the spray by volume are smaller in the centre of the distribution. With the movement of the nozzle, the small droplets tends to leave the central part of the spray under the influence of the drag force and therefore diffuse in a plume effect, which alters the shape of the spray pattern. The shape modification is complex but is seems that the phenomenon stabilises once the nozzle reaches a sufficient speed.

The estimation of the speed effect on the longitudinal spray pattern (in the forward direction) was performed on the dynamic test bench by opening the moving nozzle with the PWM nozzle body for a distance of $50 \mathrm{~mm}$ using a specially designed electronic circuitry. The spray deposits distribution under the opening zone was measured in a Petri dishes matrix layout. Figure 7 presents the result of such a measurement at a speed of $1 \mathrm{~m} / \mathrm{s}$ and a height of $50 \mathrm{~cm}$ where the sampling points are highlighted. The spray deposits distribution is displaced a few centimetres in the forward direction (X axis) from the nozzle opening interval (-25 $\mathrm{mm}<x<25 \mathrm{~mm}$ ). This can be attributed to the ballistic effect of the nozzle speed. Indeed, Fig. 8 illustrates the displacement of the longitudinal spray deposits distribution as a function of the speed at a height of $50 \mathrm{~cm}$. The mean displacement of the spray deposits distribution along the $\mathrm{X}$ axis, computed from the marginal mean, respectively 
reaches $10,27,45,67,69 \mathrm{~mm}$ for $0.1,0.5,1,1,5$ and $2 \mathrm{~m} / \mathrm{s}$. The same kind of effect is observed with increased height, the displacement at a speed of $1 \mathrm{~m} / \mathrm{s}$ reaching respectively, 16, 45 and $63 \mathrm{~mm}$ for a height of 30, 50 and $70 \mathrm{~cm}$.

Theoretically, if the aerodynamic effects were similar in continuous and discontinuous spraying, these last measurements could directly be used to compute a dynamic spray pattern taking into account the effects of speed. As a matter of fact, this trial strictly corresponds to an unit impulse input, which gives a direct estimate of the transfer function for a linear system. Unfortunately, the aerodynamic effect on the transverse spray pattern observed in Fig. 5 does not fully appear in the case of discontinuous spraying as illustrated in Fig. 9. It is therefore necessary to combine the results of the two kinds of measurements to get dynamic spray patterns $D_{v z}(x, y)$ including both aerodynamic and ballistic effects for each speed $v$ and height $z$. This is done in three steps.

(1) In the first step, the nozzle flow is multiplied by the transverse spray pattern measured for a trial at a constant speed and height. This results in a dynamic transverse spray pattern. The relative frequency $f_{v z}(y)$ is calculated from the measurement of the dynamic transverse distribution $T_{v z}(y)$,

$$
f_{v z}(y)=\frac{T_{v z}(y)}{\Xi T_{v z}(y)}
$$

where $T_{v z}(y)$ is the transverse spray deposits distribution $\mathrm{ml} / \mathrm{m}^{2}$ for continuous spraying.

The nozzle flow rate is multiplied with the relative frequency to estimate a dynamic transverse spray pattern $t_{v z}(y)$,

$$
t_{v z}(y)=q \quad f_{v z}(y)
$$


where $q$ is the nozzle flow rate in $\mathrm{ml} / \mathrm{s}$.

(2) In the second step, the measurement of the two-dimensional spray deposits distribution $L_{v z}(x, y)$ obtained with the $50 \mathrm{~mm}$ impulse for the same speed and height is used to calculate a longitudinal relative frequency $l_{v z}(x, y)$ for each position along the $\mathrm{Y}$ axis.

$$
l_{v z}(x, y)=\frac{L_{v z}(x, y)}{{ }^{+} L_{v z}(x, y) d x}
$$

where $L_{v z}(x, y)$ is the spray deposits distribution for impulse spraying in $\mathrm{ml} / \mathrm{m}^{2}$.

(3) In the last step, every point of the transverse spray pattern is multiplied with the longitudinal relative frequency at the corresponding $y$ co-ordinate to get the two-dimensional dynamic spray pattern for one particular speed and height $D_{v z}(x, y)$, what is computed with a convolution :

$$
D_{v z}(x, y)=\underbrace{\Xi}_{-\tau} \Xi_{v z}(y) l_{v z}(x-\xi, y) d \xi
$$

where $\xi$ is a space shift variable along $X$ axis.

This method neglects some aerodynamic effects on the longitudinal distribution but any other identification method should lead to a tedious convolution process and numerous measurements. 
For numerical calculus, the two-dimensional dynamic spray pattern was interpolated for $50 \mathrm{~mm}$ discrete height intervals and for discrete speed classes; [0-0.2], [0.2-0.4], [0.4-0.6], [0.6-0.75], [0.75-1.25], [1.25-1.75], [1.75-2.25] m/s.

\section{Results and discussion}

Three repetitions of the spray deposit distribution measurement were performed for three different trials: constant speed and constant height; variable speed and constant height; and constant speed and variable height. The absolute variability between the three repetitions approached 5\% (between 3 \& 7.6\% depending on the trial). These results were found consistent with the results of Smith (1992) for a similar flat fan nozzle where the three repetitions present a variability of the same amplitude (the variability was also found of the same amplitude when the spray deposits of the $\mathrm{KCl}$ solution were measured by spectrophotometry for trials with only one pass over at the test bench). As no diminution of the variability was obtained by increasing the number of passes of the nozzle, it appears that the spray pattern of flat fans nozzle is not perfectly stable. This is confirmed by the measurements of the static twodimensional spray pattern, either by filtered-back projection method (Holterman \& de Jong, 2000) or by collection in Petri dishes.

The model was used using both the static spray pattern (described as the 'static model') and the dynamic spray pattern (described as the 'dynamic model') to estimate the spray deposits distribution for the nozzle movements of the three different trials.

In order to quantify the accuracy of the predicted spray deposits model, the value of the typical absolute deviation between the model estimation and the measured 
application rate was used. This parameter $V$ which facilitates the comparison between the different trials was calculated as following:

$$
V=\frac{\underbrace{n}_{i=1}\left|d_{i}-\hat{d}_{i}\right|}{\Xi_{i=1}^{n} \hat{d}_{i}}
$$

where $V$ is the typical absolute deviation; $d_{i}$ is the modelled application rate in $\mathrm{ml} / \mathrm{m}^{2}$ at one point; $\hat{d}_{i}$ is the measured application rate in $\mathrm{ml} / \mathrm{m}^{2}$ at one point; and $n$ is the number of measurement points.

This last value was also a good criteria to compare the modelling errors with the spray deposits variability.

\subsection{Constant speed and height}

The spray deposit distribution were measured and simulated at the constant speed of $1 \mathrm{~m} / \mathrm{s}$ and height of $500 \mathrm{~mm}$. The application rate was uniform along the $X$ axis. Figure 10 presents the application rates (spray deposits) modelled and measured every $70 \mathrm{~mm}$ along the $Y$ axis (three repetitions). It appears that the transverse spray deposit distribution is badly predicted by the static model. It was overestimated in the central part of the distribution $(-250<y<250 \mathrm{~mm})$, reaching $25 \mathrm{ml} / \mathrm{m}^{2}$ when the mean measured maximum only reaches $17 \mathrm{ml} / \mathrm{m}^{2}$. On the contrary, it was underestimated for the outer edges. These errors result in a high values of $V(32.6 \%)$. It is clear that these errors are systematic and exceed the variability of the spray deposits. The dynamic model furnished a far better estimation of the transverse spray deposits distribution and the remaining variability was contained within the spray deposits variability between the three repetitions. This was attested by the value of $V$ 
decreasing to $5.9 \%$, which is of the same order of magnitude as the observed variability between the three repetitions.

\subsection{Speed variation and constant height}

The spray deposit distribution was simulated for sinusoidal speed $[1+0,2 \pi \sin (2 \pi t)] \mathrm{m} / \mathrm{s}$ and constant height of $500 \mathrm{~mm}$. This movement (amplitude of 10 $\mathrm{cm}$ at $1 \mathrm{~Hz}$ frequency) is representative of energetic boom movements such as those created by an obstacle on the field. It was chosen to validate the model in extreme conditions. The spray deposits distribution was measured on a $1 \mathrm{~m}$ by $1.4 \mathrm{~m}$ surface (corresponding to one sinusoidal cycle) using a $100 \mathrm{~mm}$ spacing square grid. Figures $11 a$ to $11 c$ present the application rate measured and modelled. The spray deposits distribution was best estimated by the dynamic model, as the value of $V$ decreases from $26.2 \%$ to $11.1 \%$. Longitudinally, the higher application rates corresponded to the lowest speed in the forward direction. Figure 12 presents the mean application rate along the $X$ axis. When the static model is used, a small lag appears, caused by the ballistic effect. The lag is bigger when the mean application rate decreases, which corresponds to the highest speeds. When using the dynamic model, this phase lag disappeared but a slight smoothing affected the curve. Figure 13 presents the mean application rate along the transversal $Y$ axis. As in the constant speed trial with the static model, the application rate is overestimated in the central part of the distribution and underestimated at the edges. The effect was again well compensated by the dynamic model.

\subsection{Constant speed and variable height}


The spray deposit distribution was simulated at constant speed ( $1 \mathrm{~m} / \mathrm{s})$ and rapid height variation (linear variation from 700 to $300 \mathrm{~mm}$ within 2.5 metres). The spray deposit distribution was measured within a trapezoidal surface, the largest smallest edges corresponding respectively to 700 and $300 \mathrm{~mm}$ height. Figures $14 \mathrm{a}$ to $14 \mathrm{c}$ present the application rate measured and estimated using respectively the static and dynamic models. The effect of the height variation was well predicted in both cases but here again, the application rate was best predicted with the dynamic model, the value of $V$ decreasing from $25.9 \%$ to $11.5 \%$. The aerodynamic effect of the nozzle speed is again the main source of errors with an overestimation of the deposits in the nozzle axis, as illustrated by Fig. $15 a$ presenting the differences between the measured and modelled application rate using the static model. When the dynamic model is used, the differences decrease and are more randomly located (Fig. 15b).

\subsection{Discussion}

These results still need to be extended to other speeds, pressures and other nozzles but the effect should be present for other flat fan nozzles as their spray pattern and droplets sizes are similar. Similar effects should also be observed for other nozzle designs if a significant proportion of fine droplets is present in the spray. The effect of adjacent nozzles on a spray boom should also be investigated. Their interaction could affect the result of the spray deposits distribution even if the twist angle limits the crossing of the sprays. Most probably, the effect of the nozzle speed should be present as the related plume effect is classically observed in field spraying.

Furthermore, as the method used to measure the dynamic pattern of the nozzle is quite work intensive, it would be interesting to model the effect of the nozzle speed on the static spray pattern. A patternator measurement would probably be insufficient to predict accurately the dynamic spray pattern, as the aerodynamic effects are linked to the droplets diameter, but the approach could reveal successful if the effect of the 
nozzle speed is accounted separately for each diameter class, i.e. on the basis of granulometer measurements. This method could finally be further extended to take into account drift effect.

\section{Conclusions}

A mathematical model of the spray application process is proposed. Using constant distance intervals along the nozzle trajectory, the spray deposits distribution is calculated by a convolution of the two-dimensional spray pattern with the time spent in each position interval. The application of the model states that, on one hand, the trajectory of the nozzle is available and, on the other hand, that for the operational parameters the two-dimensional spray pattern of the nozzle are known. When these conditions are met, the use of a dynamic spray pattern instead of the static spray pattern improves the quality of prediction for the three basic movements applied to the spray nozzle. This improvement is included between $80 \%$ for the constants speed and height trial and $55 \%$ for the speed variation and height variation trails. The remaining errors may notably be caused by the interpolations, the model spatial resolution and the spray pattern variability. This last cause was found to be particularly important for this flat fan nozzle what leaves few margins to further improve the model. Furthermore, the variability between the three repetitions of the same trial was found close of the dynamic model error amplitude. The dynamic model allow a prediction of the spray deposits under a moving nozzle with a precision of about $10 \%$.

\section{References}

de Jong E; Van de Zande J-C; Stallinga H (2000). The effects of vertical and horizontal boom movements on the uniformity of spray distribution. EurAgEng 
Paper No 00-PM-15, AgEng 2000 International Conference on Agricultural Engineering, Warwick, United-Kingdom, 8 pp.

Giles D K; Comino A (1990). Droplet size and spray pattern characteristics of an electronic flow controller for spray nozzle. Journal of Agricultural Engineering Research, 47, 249-267

Holterman H J; de Jong A (2000). Computing static two-dimensional patterns using patternator observations. EurAgEng 2000 Paper No 00-PM-067, AgEng 2000 International Conference on Agricultural Engineering, Warwick, UnitedKingdom, 2 pp.

Lardoux Y (2002). Etude de la répartition au sol des produits phytosanitaires sous une rampe en mouvement a partir d'une modélisation dynamique - application à la définition de méthodes d'évaluation des pulvérisateurs à jet projetés. [Study of the ground spray deposits distribution of phytopharmaceuticals under a moving boom based on a dynamical modelling - application to the definition of a evaluation methodology of power operated hydraulic sprayers.] PhD Thesis, Ecole Nationale Supérieure Agronomique de Montpellier, France, pp. 333

Lebeau F; Bouchat X; Ruter R; Destain M-F (2002). Spray pattern simulation for standardisation of boom behavior tests. Aspects of Applied Biology 66, 427-434.

Lund I; Matzen R (1996). Analysis of droplets in a three-dimensional pattern in the spray from a field sprayer. EurAgEng Paper No 96A-123, AgEng 96 International Conference on Agricultural Engineering, Madrid, Spain, pp. 8

Nation H J (1976). Spray nozzle performance and effects of boom height on distribution. NIAE Departmental Note DN/S/77/1925, National Institute of Agricultural Engineering, Silsoe, UK, pp. 27

Ramon H; De Baerdemaeker J (1997). Spray boom motion and spray distribution : part 1, derivation of a mathematical relation. Journal of Agricultural Engineering Research, 66, 23-29, doi:10.1006/jaer.1996.0114 
Ramon H; Missotten B; De Baerdemaeker J (1997). Spray boom motion and spray distribution : part 2, experimental validation of the mathematical relation and simulation results. Journal of Agricultural Engineering Research, 66, 31-39, doi: 10.1006/jaer.1996.0115

Sinfort C (1991). Contribution à la définition d'une méthodologie d'évaluation des rampes de traitements phytosanitaires à l'aide d'un banc de simulation de pistes. [Contribution to the definition of an evaluation methodology of the phytopharmaceutical treatment spray booms using a track simulator.] $\mathrm{PhD}$ Thesis, Ecole Nationale Supérieure Agronomique de Montpellier, France, pp. 175

Smith D B (1992). A proposal for pre-field broadcast spray deposit evaluations. Transactions of the ASAE, 35(1), 33-37

Tian L; Zheng J (2000). Dynamic deposition pattern simulation of modulated spraying. Transactions of the ASAE, 43(1), 5-11 


\section{Notation}

$\hat{d}_{i} \quad$ measured application rate at one point, $\mathrm{ml} / \mathrm{m}^{2}$

$d_{i} \quad$ modelled application rate at one point, $\mathrm{ml} / \mathrm{m}^{2}$

$k(x, y) \quad$ function describing time interval spent by a nozzle at the position $(x, y)$, $\mathrm{s} / \mathrm{m}^{2}$

$D(x, y) \quad$ function describing the two-dimensional spray pattern, $\mathrm{ml} / \mathrm{m}^{2} \mathrm{~s}$ $I_{v z}(x, y) \quad$ longitudinal relative frequency for each position along $y$ axis, $\mathrm{m}^{-1}$ $t_{v z}(y)$ relative frequency calculated from the measurement of the dynamic transverse distribution, $\mathrm{m}^{-1}$

$D_{0.1} \quad$ diameter for $10 \%$ of the spray by volume, $\mu \mathrm{m}$

$D_{0.5} \quad$ diameter for $50 \%$ of the spray by volume, $\mu \mathrm{m}$

$D_{0.9} \quad$ diameter for $90 \%$ of the spray by volume, $\mu \mathrm{m}$

$d t_{v z}(y) \quad$ dynamic transverse spray pattern, $\mathrm{ml} / \mathrm{ms}$

$D_{v z}(x, y) \quad$ function describing the two-dimensional dynamic spray patterns including both aerodynamic and ballistic effects for each speed $v$ and height $z, \mathrm{ml} / \mathrm{m}^{2} \mathrm{~s}$

$q \quad$ nozzle flow rate, $\mathrm{ml} / \mathrm{s}$

$R(x, y) \quad$ spray deposit distribution, $\mathrm{ml} / \mathrm{m}^{2}$

$L_{v z}(x, y) \quad$ spray deposits distribution for impulse spraying, $\mathrm{ml} / \mathrm{m}^{2}$

$T_{v z}(y)$ the transverse spray deposits distribution for continuous spraying, $\mathrm{ml} / \mathrm{m}^{2}$

V typical absolute deviation

$v \quad$ nozzle speed, $\mathrm{m} / \mathrm{s}$

$n \quad$ number of spray deposit measurement points

$x, y \& z \quad$ co-ordinates along the forward, transverse and vertical directions, $\mathrm{m}$

$\psi \quad$ space shifting variable along $y$ axis, $\mathrm{m}$

$\xi \quad$ space shift variable along $x$ axis, m 


\section{List of Figures}

Fig. 1. Reference axes

Fig. 2. Model of the spray deposit distribution shown as the sum of separate spray deposit (ellipses) for each doted location on the travel trajectory

Fig. 3. Dynamic test bench: (1) travelling boom; (2) controller; (3) servomotor; (4) nozzle; (5) spray collectors; (6) spray table

Fig. 4. Pulse width modulation nozzle body

Fig. 5. Effect of the speed on the transverse spray deposit distribution, $50 \mathrm{~mm}$ interval, 50 cm height: +, $0.1 \mathrm{~m} / \mathrm{s} ;$ ○, $0.3 \mathrm{~m} / \mathrm{s} ;{ }^{*}, 0.5 \mathrm{~m} / \mathrm{s} ; \times, 0.7 \mathrm{~m} / \mathrm{s} ; \square, 1 \mathrm{~m} / \mathrm{s} ; \Delta, 1.5 \mathrm{~m} / \mathrm{s}$;

$$
\diamond, 2 \mathrm{~m} / \mathrm{s}
$$

Fig. 6. Granulometry of the Teejet XR11003VK flat-fan nozzle at a perssure of 2 bar and height of $55 \mathrm{~cm}$ : $\mathrm{D}_{0.1}$, diameter for 10 per cent by volume ; $\mathrm{D}_{0.5}$, diameter for 50 per cent by volume ; $\mathrm{D}_{0.9}$, diameter for 90 per cent by volume

Fig. 7. Measured spray deposits for a $50 \mathrm{~mm}$ length of impulse spraying at a speed of $1 \mathrm{~m} / \mathrm{s}$ and $50 \mathrm{~cm}$ height, $50 \mathrm{~mm}$ by $50 \mathrm{~mm}$ resolution

Fig. 8. Effect of the speed on the mean longitudinal spray deposits distribution for a $50 \mathrm{~mm}$ length impulse spraying, $70 \mathrm{~mm}$ interval, $50 \mathrm{~cm}$ height: +, $0.1 \mathrm{~m} / \mathrm{s} ; \circ, 0.5 \mathrm{~m} / \mathrm{s}$;

$$
\text { *, } 1 \mathrm{~m} / \mathrm{s} ; \square, 1.5 \mathrm{~m} / \mathrm{s} ; \times, 2 \mathrm{~m} / \mathrm{s}
$$


Fig. 9. Effect of the speed on the transverse spray deposit distribution for a $50 \mathrm{~mm}$ length impulse spraying, $50 \mathrm{~mm}$ interval, $50 \mathrm{~cm}$ height: +, $0.1 \mathrm{~m} / \mathrm{s} ; \circ, 0.5 \mathrm{~m} / \mathrm{s}$; *,

$$
1 \mathrm{~m} / \mathrm{s} ; \times, 1.5 \mathrm{~m} / \mathrm{s} ; \square, 2 \mathrm{~m} / \mathrm{s}
$$

Fig. 10. Comparison of transverse spray deposit distribution at a speed of $1 \mathrm{~m} / \mathrm{s}$ and 50 cm height; +, measured values (3 repetitions); *, static modelling; ○, dynamic modelling

Fig. 11. Spray deposit distribution for a sinusoidal speed of $[1+0,2 \pi \sin (2 \pi t)] \mathrm{m} / \mathrm{s}$ and an height of $50 \mathrm{~cm}$; (a) Measured, (b) Modelled using static spray pattern, (c) Modelled using dynamic spray pattern

Fig. 12. Comparison of mean longitudinal spray deposit distribution for a sinusoidal speed of $[1+0,2 \pi \sin (2 \pi \mathrm{t})] \mathrm{m} / \mathrm{s}$ and an height of $50 \mathrm{~cm}$; $\square$, measured values; *, static modelling; o, dynamic modelling

Fig. 13. Comparison of transverse spray deposit distribution for a sinusoidal speed of $[1+0,2 \pi \sin (2 \pi t)] \mathrm{m} / \mathrm{s}$ and an height of $50 \mathrm{~cm}$; $\circ$, measured values; +, static modelling; *, dynamic modelling

Fig. 14. Spray deposit distribution for a speed of $1 \mathrm{~m} / \mathrm{s}$ and a linear height variation from 700 to 300 mm within 2.5 metres; (a) Measured, (b) Modelled using static spray pattern, (c) Modelled using dynamic spray pattern

Fig. 15. Difference between measured and modelled spray deposit distribution for a speed of $1 \mathrm{~m} / \mathrm{s}$ and a linear height variation from 700 to $300 \mathrm{~mm}$ within 2.5 metres; 
(a) Modelled using static spray pattern, (b) Modelled using dynamic spray pattern 


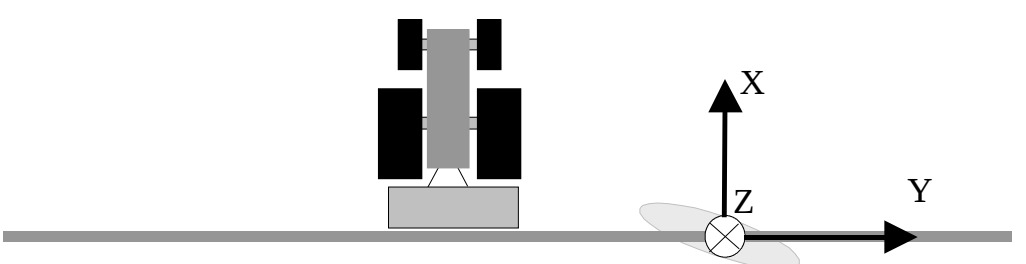

Fig. 1. Reference axes 


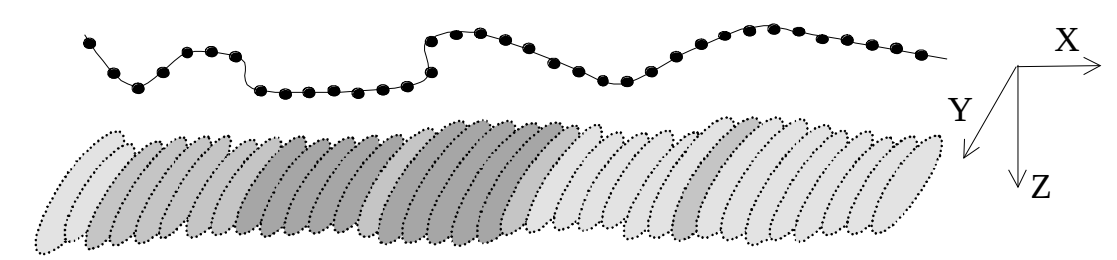

Fig. 2. Model of the spray deposit distribution shown as the sum of separate spray deposit (ellipses) for each doted location on the travel trajectory 


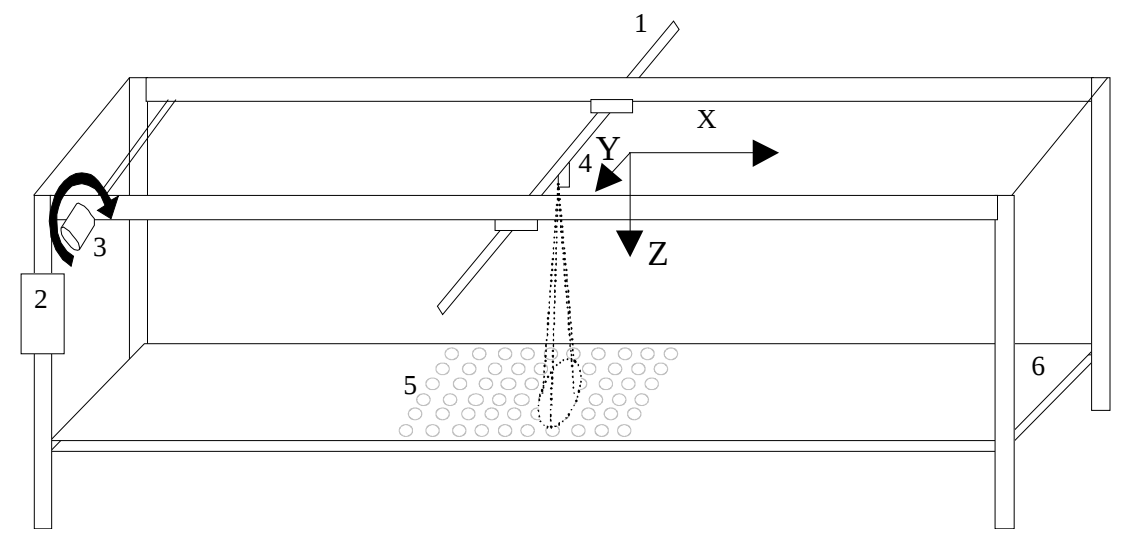

Fig. 3. Dynamic test bench: (1) travelling boom; (2) controller; (3) servomotor; (4) nozzle; (5) spray collectors; (6) spray table 


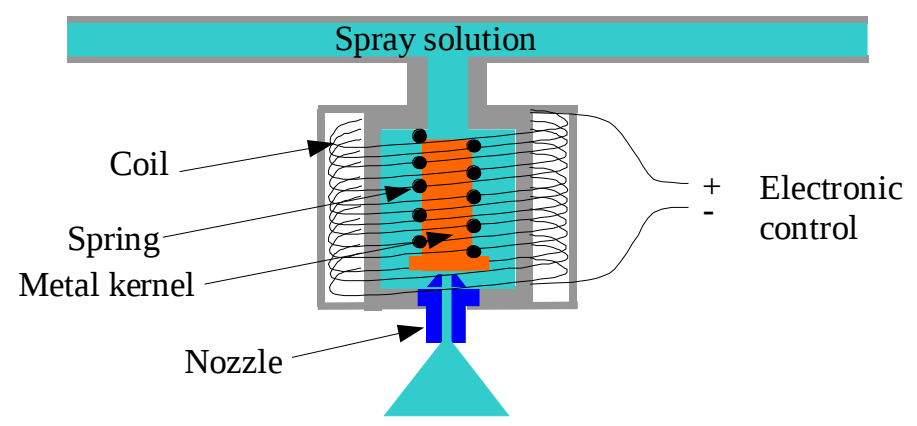

Fig. 4. Pulse width modulation nozzle body 


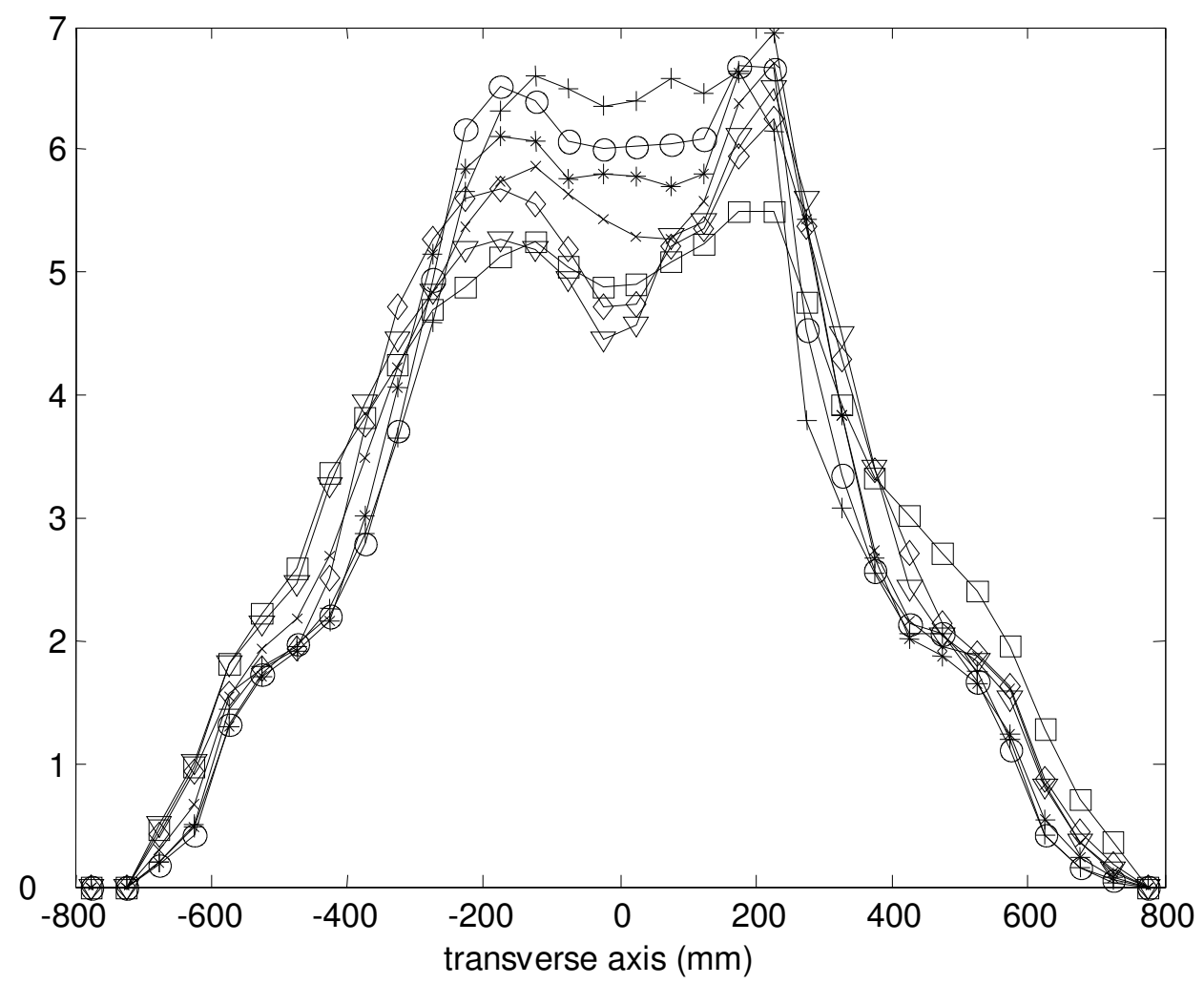

Fig. 5. Effect of the speed on the transverse spray deposit distribution, $50 \mathrm{~mm}$ interval, $50 \mathrm{~cm}$ height: +, $0.1 \mathrm{~m} / \mathrm{s} ; \circ, 0.3 \mathrm{~m} / \mathrm{s} ;{ }^{*}, 0.5 \mathrm{~m} / \mathrm{s} ; \times, 0.7 \mathrm{~m} / \mathrm{s} ; \square, 1 \mathrm{~m} / \mathrm{s} ; \Delta, 1.5 \mathrm{~m} / \mathrm{s}$; $\diamond, 2 \mathrm{~m} / \mathrm{s}$ 


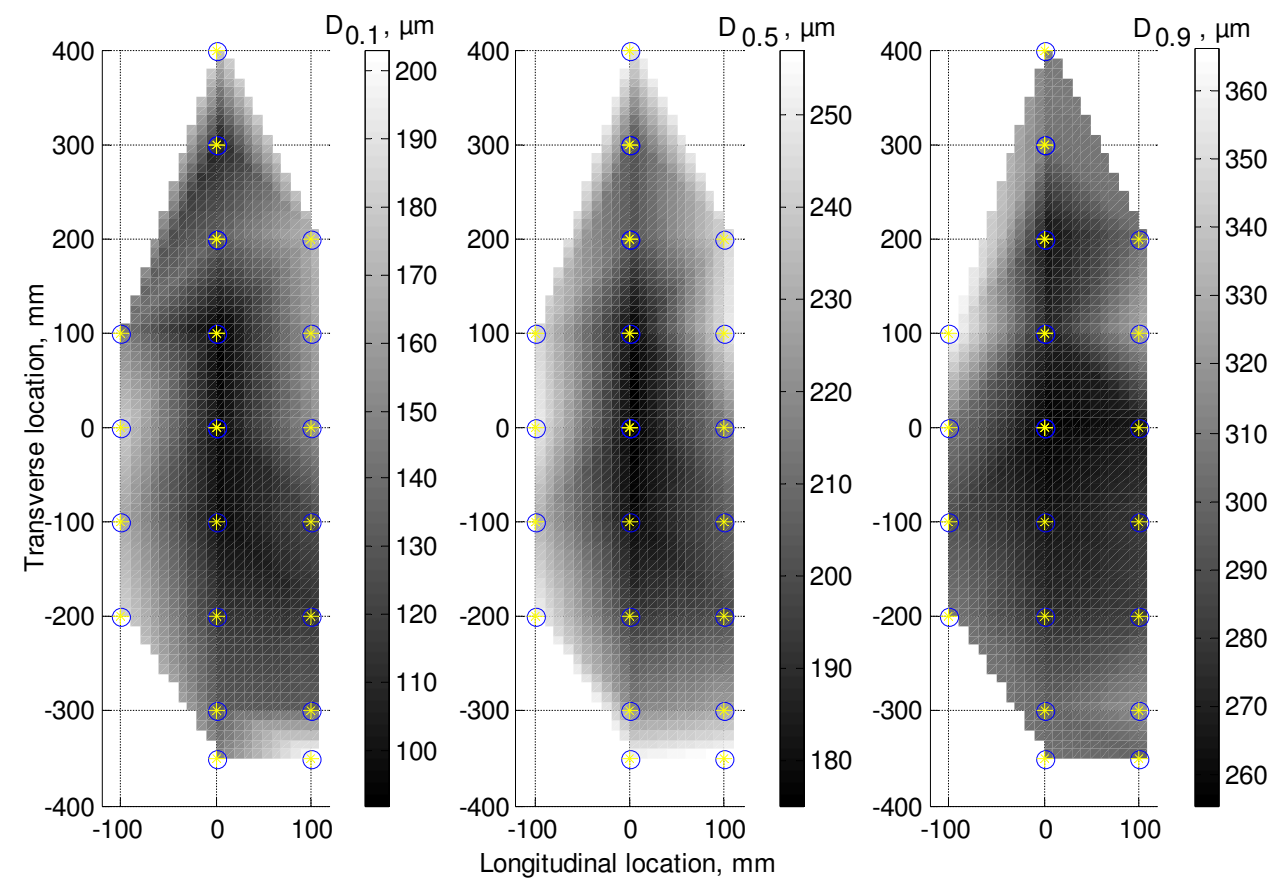

Fig. 6. Granulometry of the Teejet XR11003VK flat-fan nozzle at a perssure of 2 bar and height of $55 \mathrm{~cm}$ : $\mathrm{D}_{0.1}$, diameter for 10 per cent by volume ; $\mathrm{D}_{0.5}$, diameter for 50 per cent by volume ; $\mathrm{D}_{0.9}$, diameter for 90 per cent by volume 


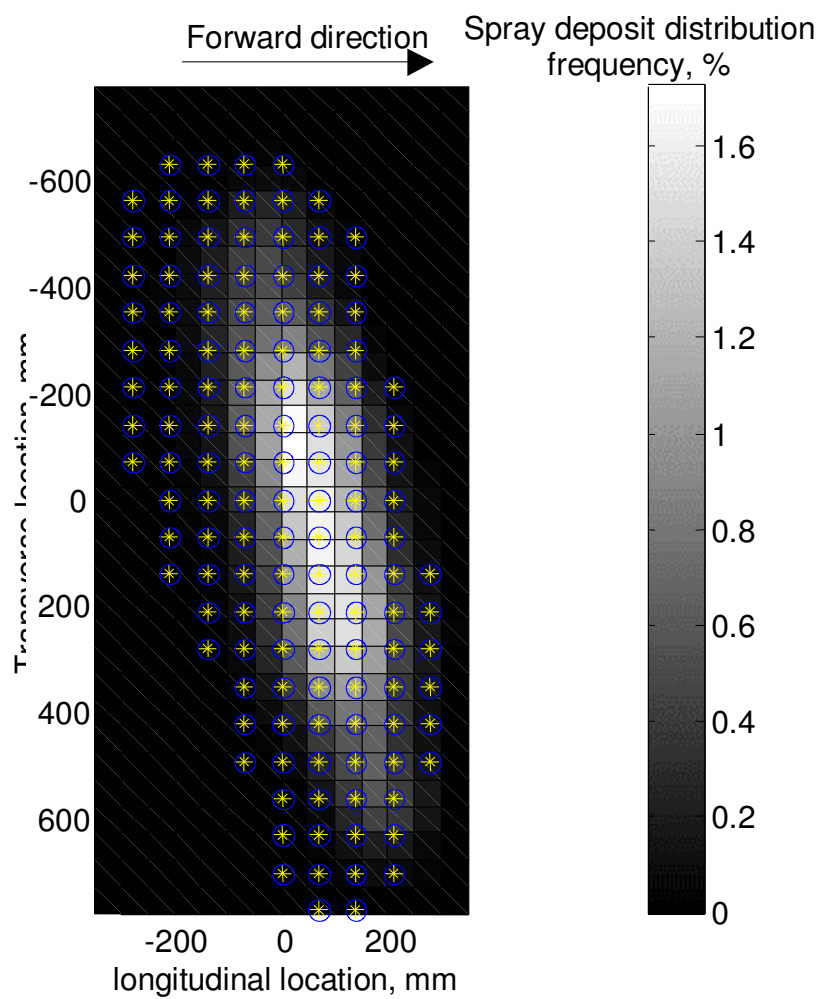

Fig. 7. Measured spray deposits for a $50 \mathrm{~mm}$ length of impulse spraying at a speed of $1 \mathrm{~m} / \mathrm{s}$ and $50 \mathrm{~cm}$ height, $50 \mathrm{~mm}$ by $50 \mathrm{~mm}$ resolution 


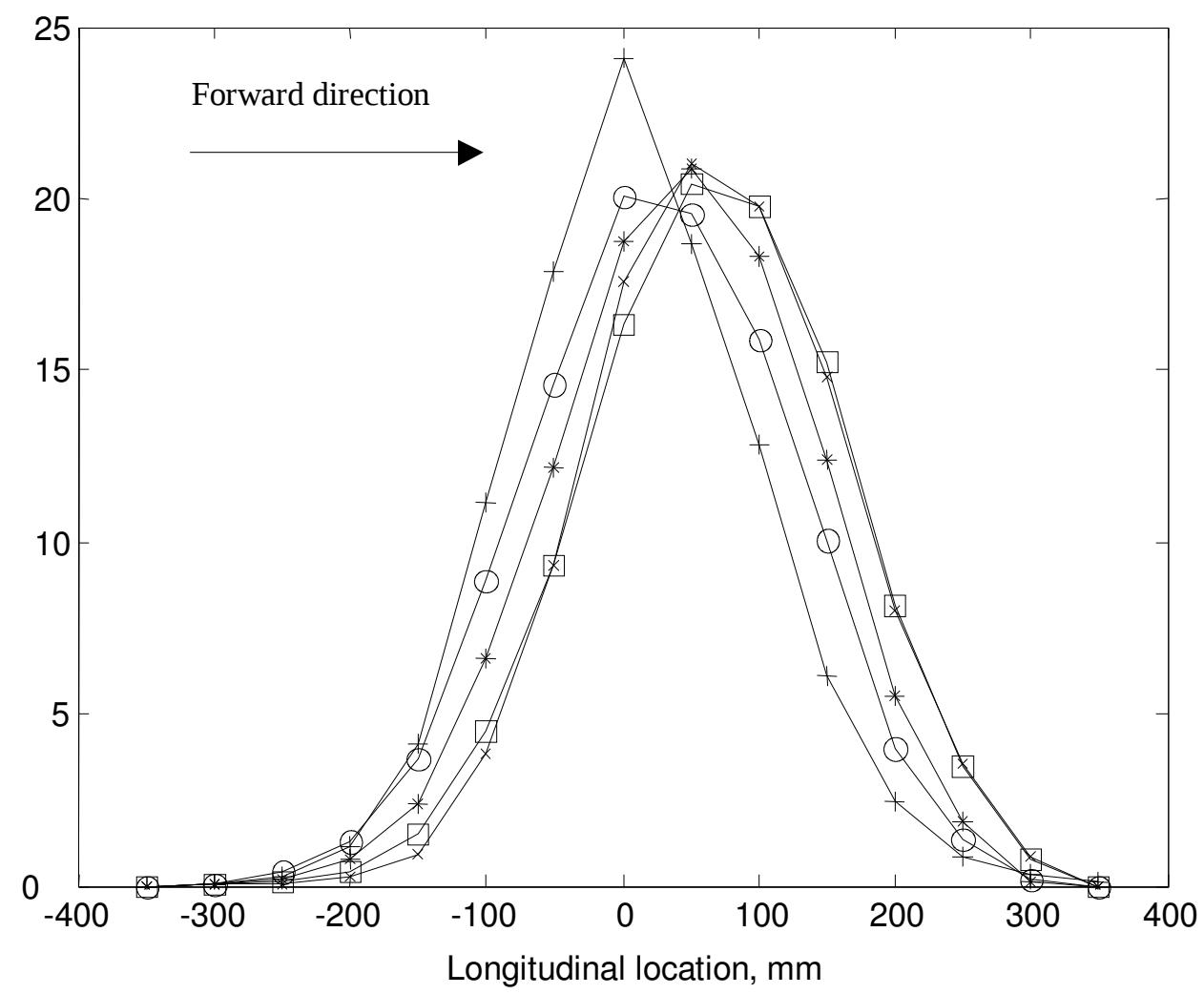

Fig. 8. Effect of the speed on the mean longitudinal spray deposits distribution for a $50 \mathrm{~mm}$ length impulse spraying, $70 \mathrm{~mm}$ interval, $50 \mathrm{~cm}$ height: +, $0.1 \mathrm{~m} / \mathrm{s} ;$ ○, $0.5 \mathrm{~m} / \mathrm{s}$; *, $1 \mathrm{~m} / \mathrm{s} ; \square, 1.5 \mathrm{~m} / \mathrm{s} ; \times, 2 \mathrm{~m} / \mathrm{s}$ 


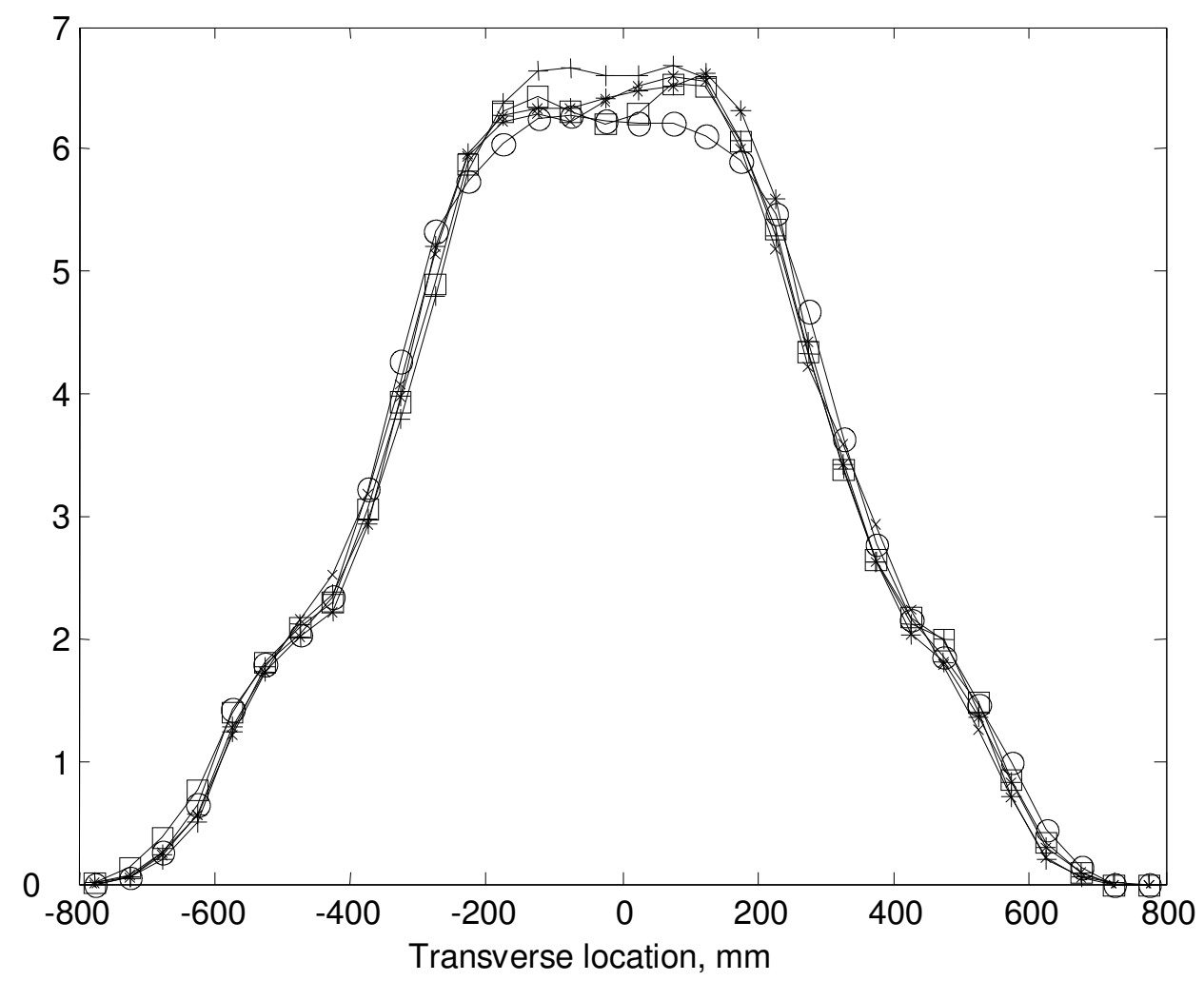

Fig. 9. Effect of the speed on the transverse spray deposit distribution for a $50 \mathrm{~mm}$ length impulse spraying, $50 \mathrm{~mm}$ interval, $50 \mathrm{~cm}$ height: +, $0.1 \mathrm{~m} / \mathrm{s} ; \circ, 0.5 \mathrm{~m} / \mathrm{s}$; *, $1 \mathrm{~m} / \mathrm{s} ; \times, 1.5 \mathrm{~m} / \mathrm{s} ; \square, 2 \mathrm{~m} / \mathrm{s}$ 


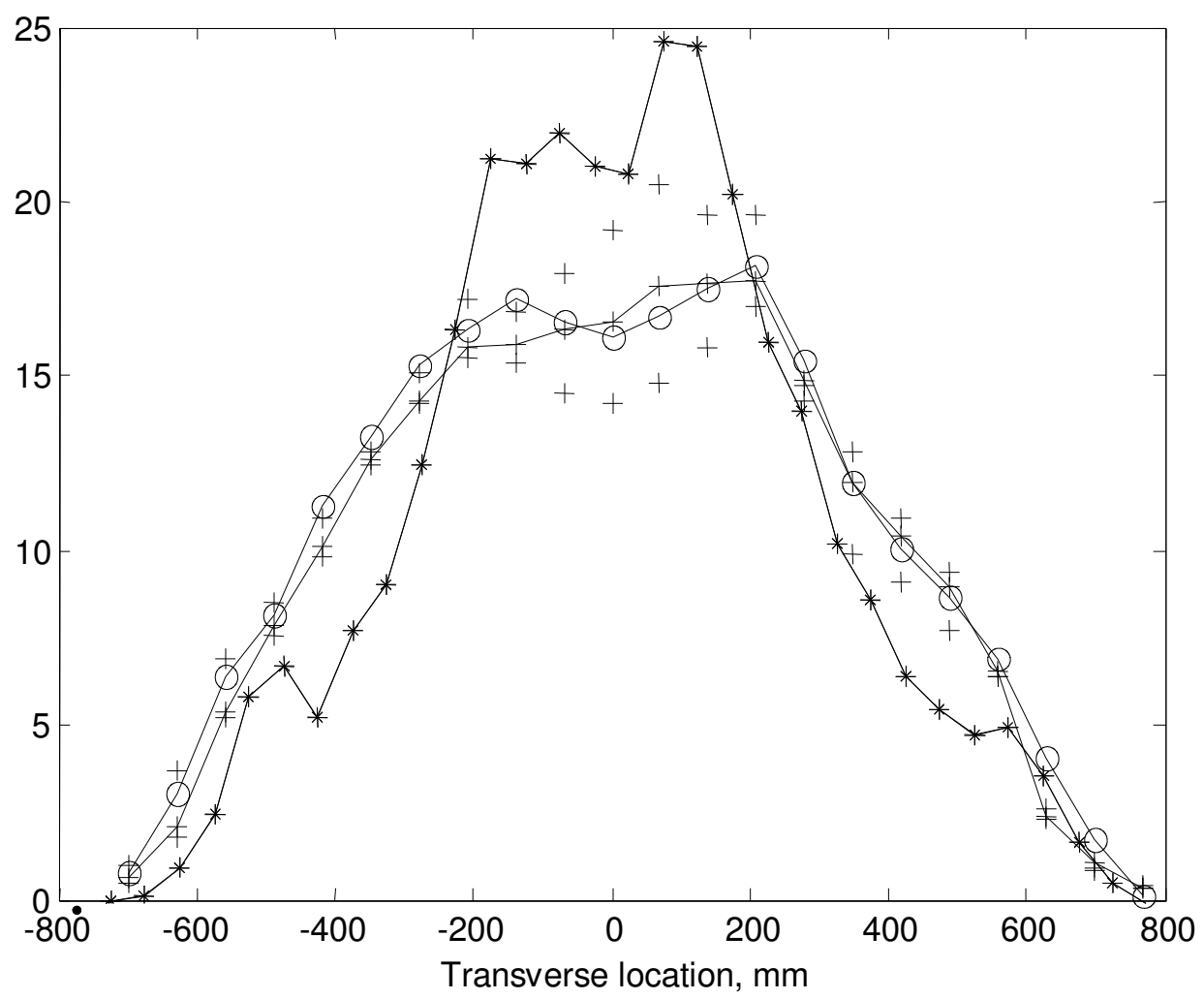

Fig. 10. Comparison of transverse spray deposit distribution at a speed of $1 \mathrm{~m} / \mathrm{s}$ and 50 cm height; +, measured values (3 repetitions); *, static modelling; $\circ$, dynamic modelling 


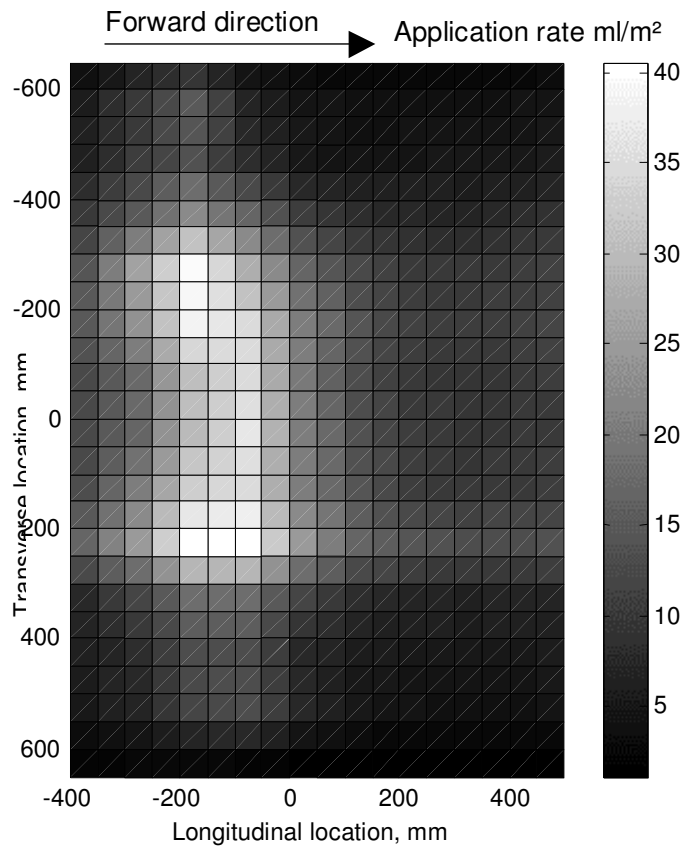

(a)

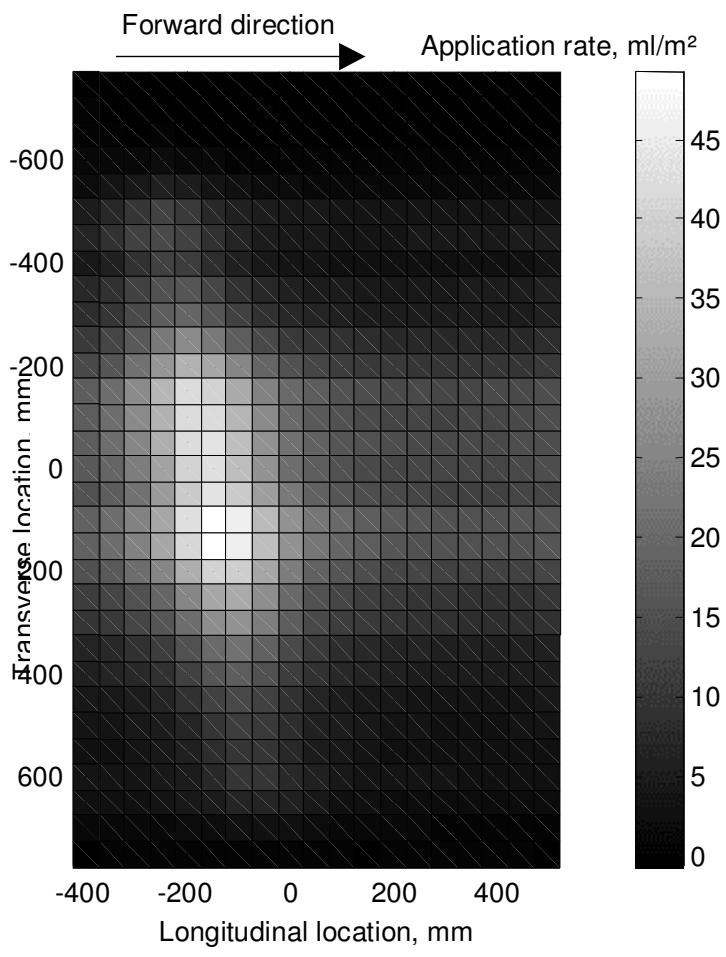

(b) 


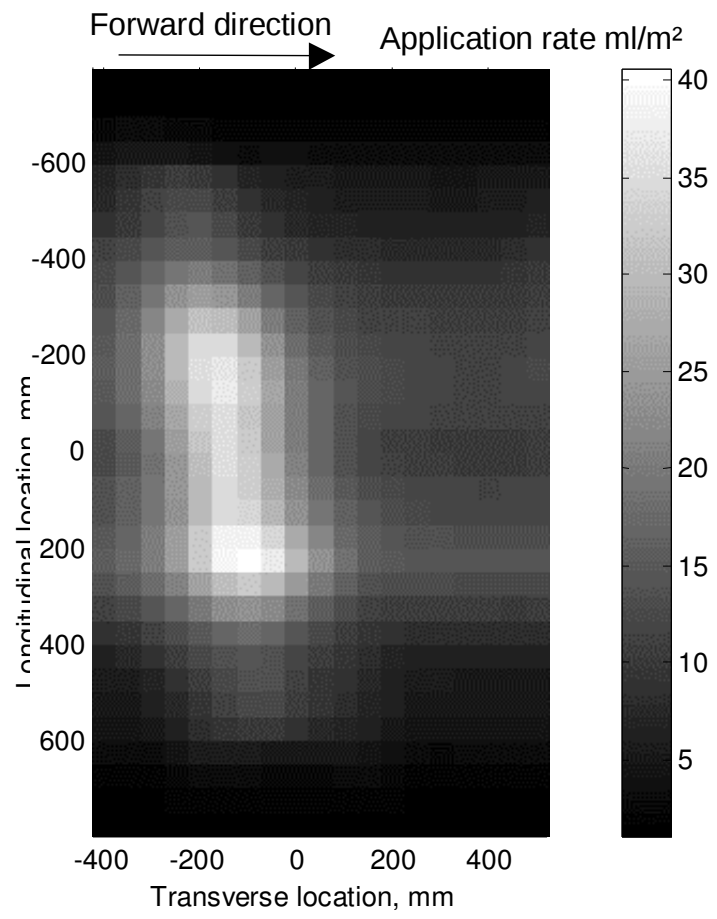

(c)

Fig. 11. Spray deposit distribution for a sinusoidal speed of $[1+0,2 \pi \sin (2 \pi t)] \mathrm{m} / \mathrm{s}$ and an height of $50 \mathrm{~cm}$; (a) Measured, (b) Modelled using static spray pattern, (c)

Modelled using dynamic spray pattern 


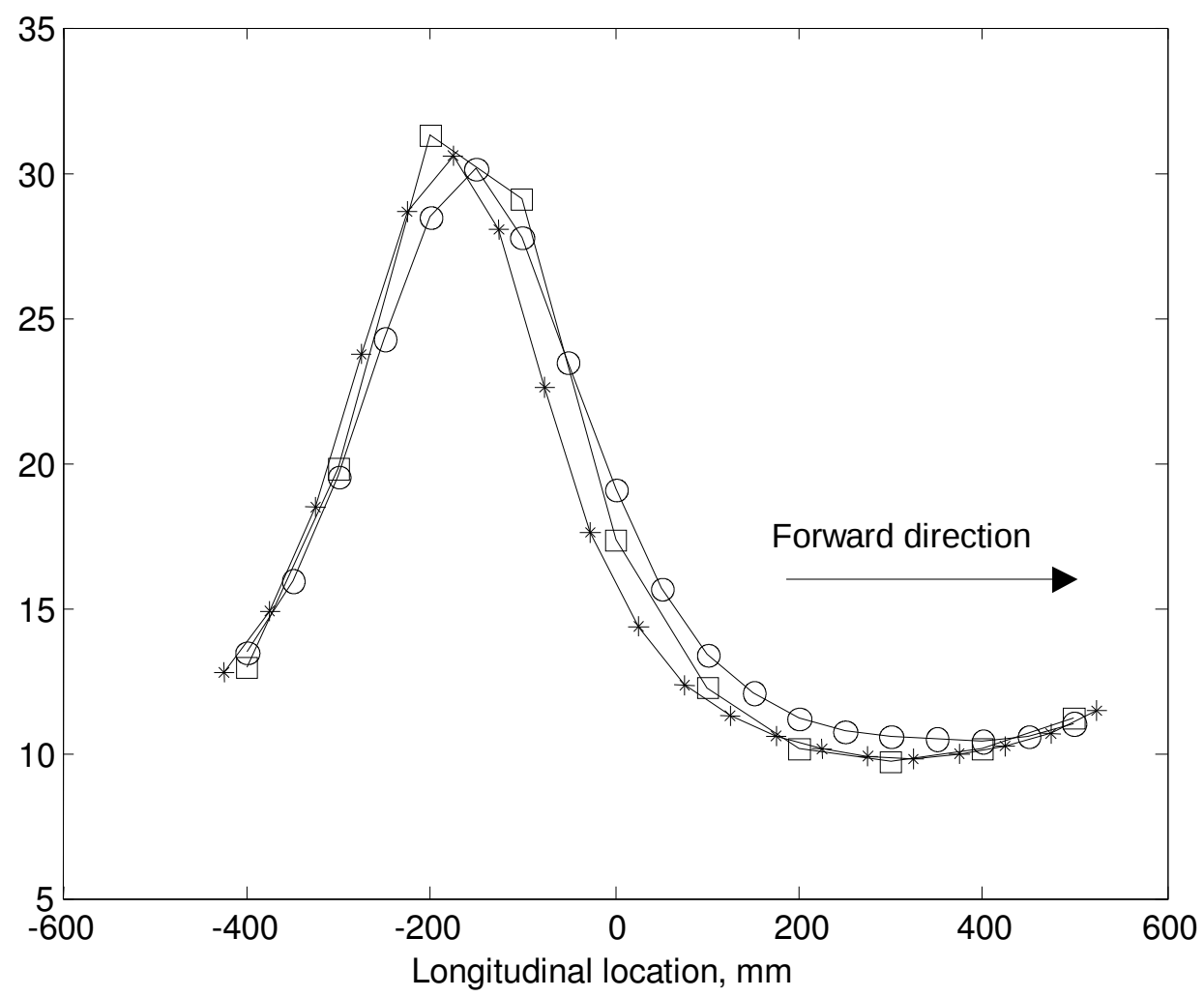

Fig. 12. Comparison of mean longitudinal spray deposit distribution for a sinusoidal speed of $[1+0,2 \pi \sin (2 \pi \mathrm{t})] \mathrm{m} / \mathrm{s}$ and an height of $50 \mathrm{~cm}$; $\square$, measured values; *, static modelling; ○, dynamic modelling 


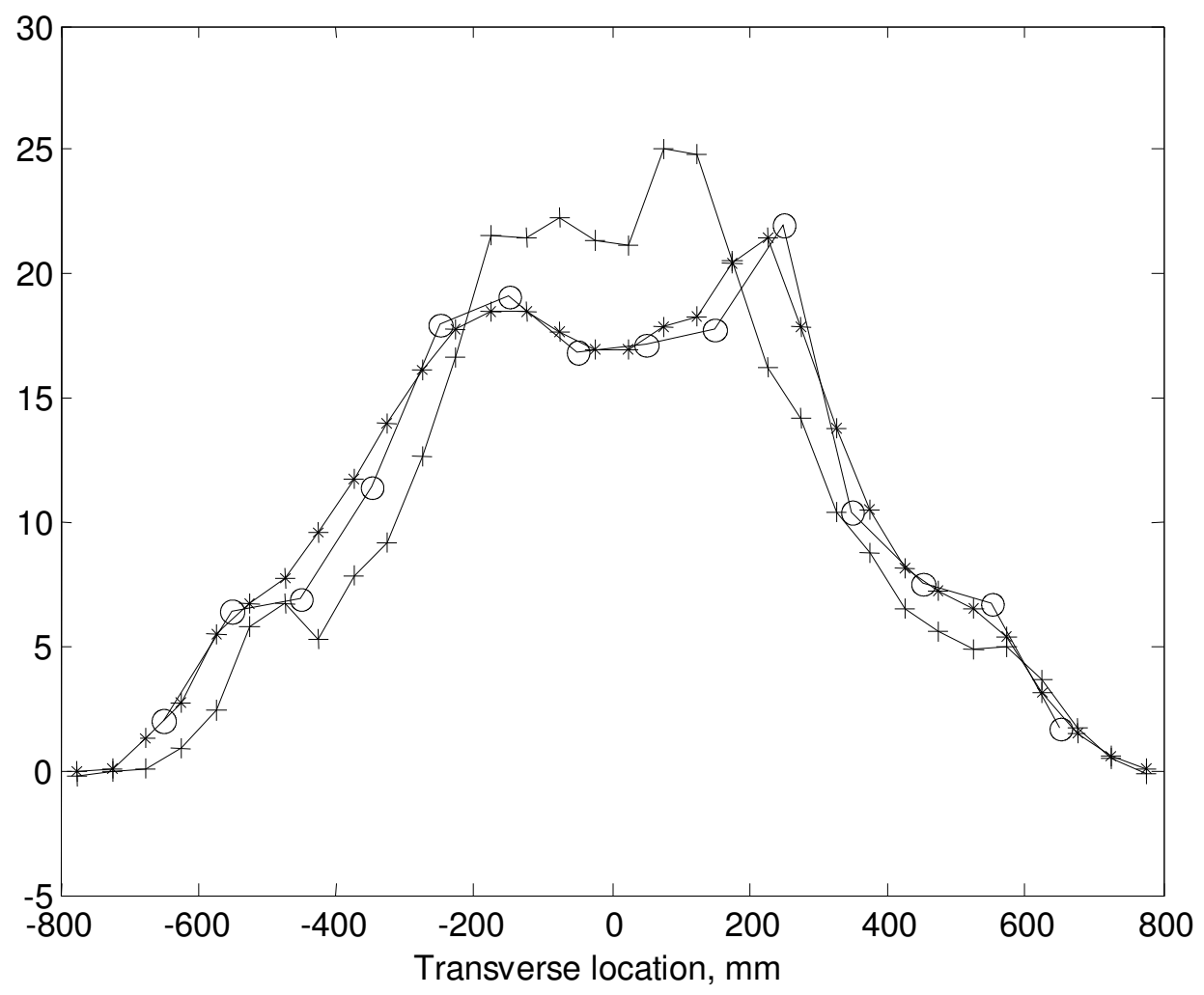

Fig. 13. Comparison of transverse spray deposit distribution for a sinusoidal speed of $[1+0,2 \pi \sin (2 \pi t)] \mathrm{m} / \mathrm{s}$ and an height of $50 \mathrm{~cm}$; $\circ$, measured values; +, static modelling; *, dynamic modelling 
Application rate, $\mathrm{ml} / \mathrm{m}^{2}$

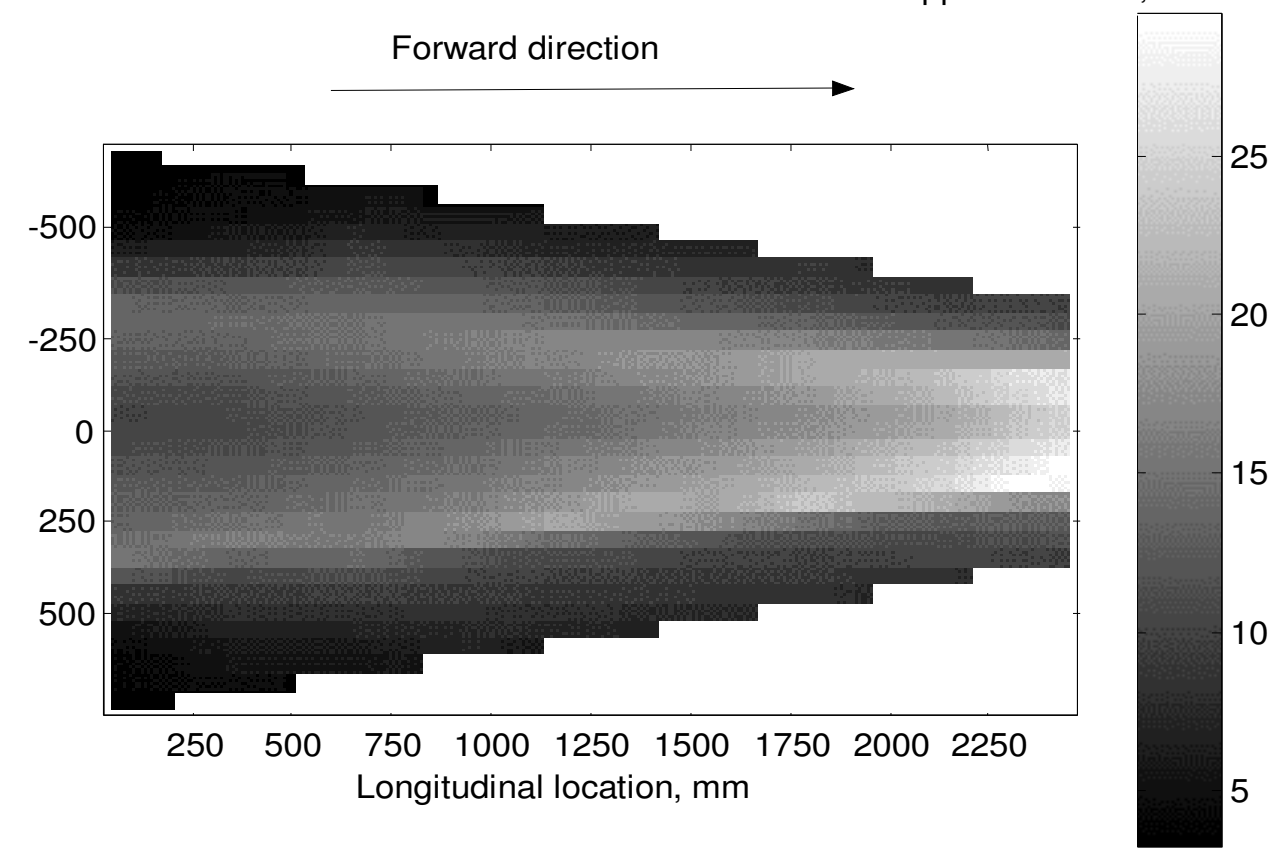

(a)

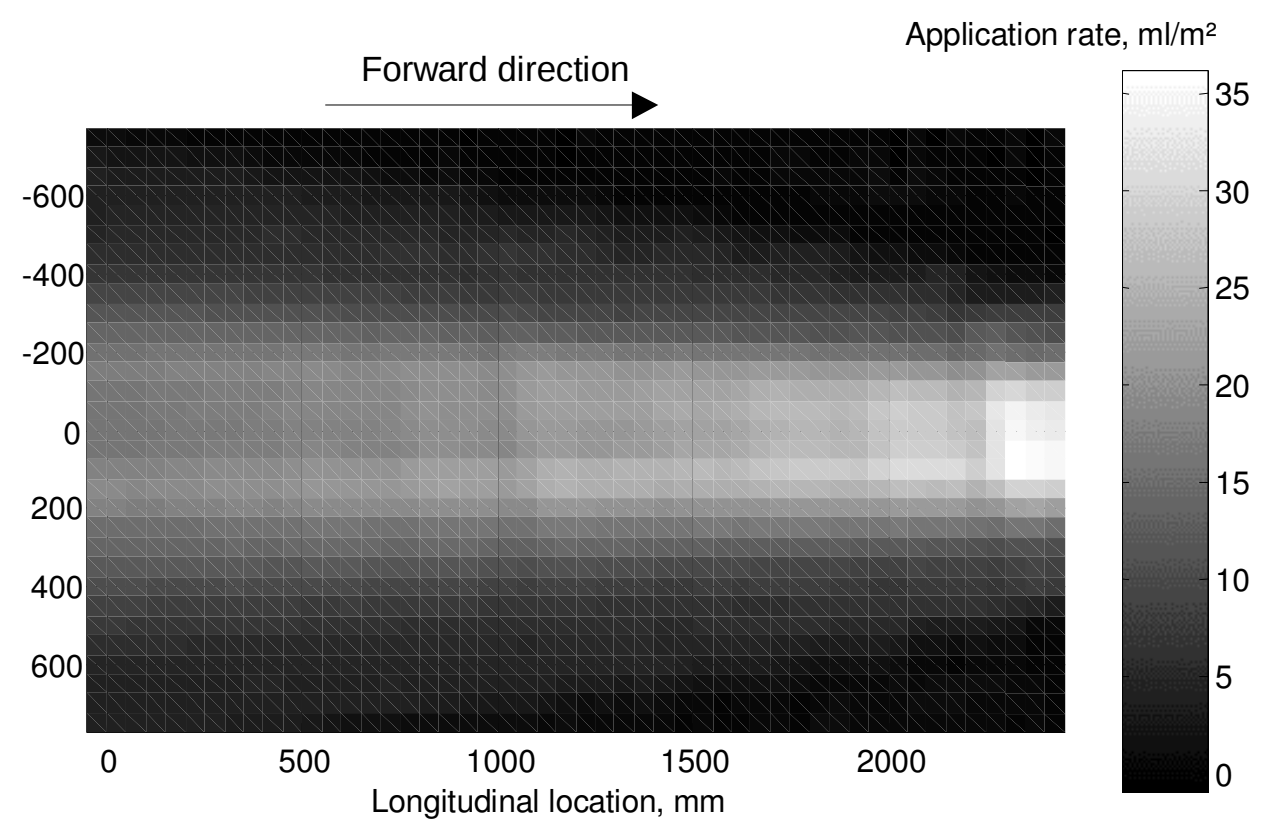

(b) 


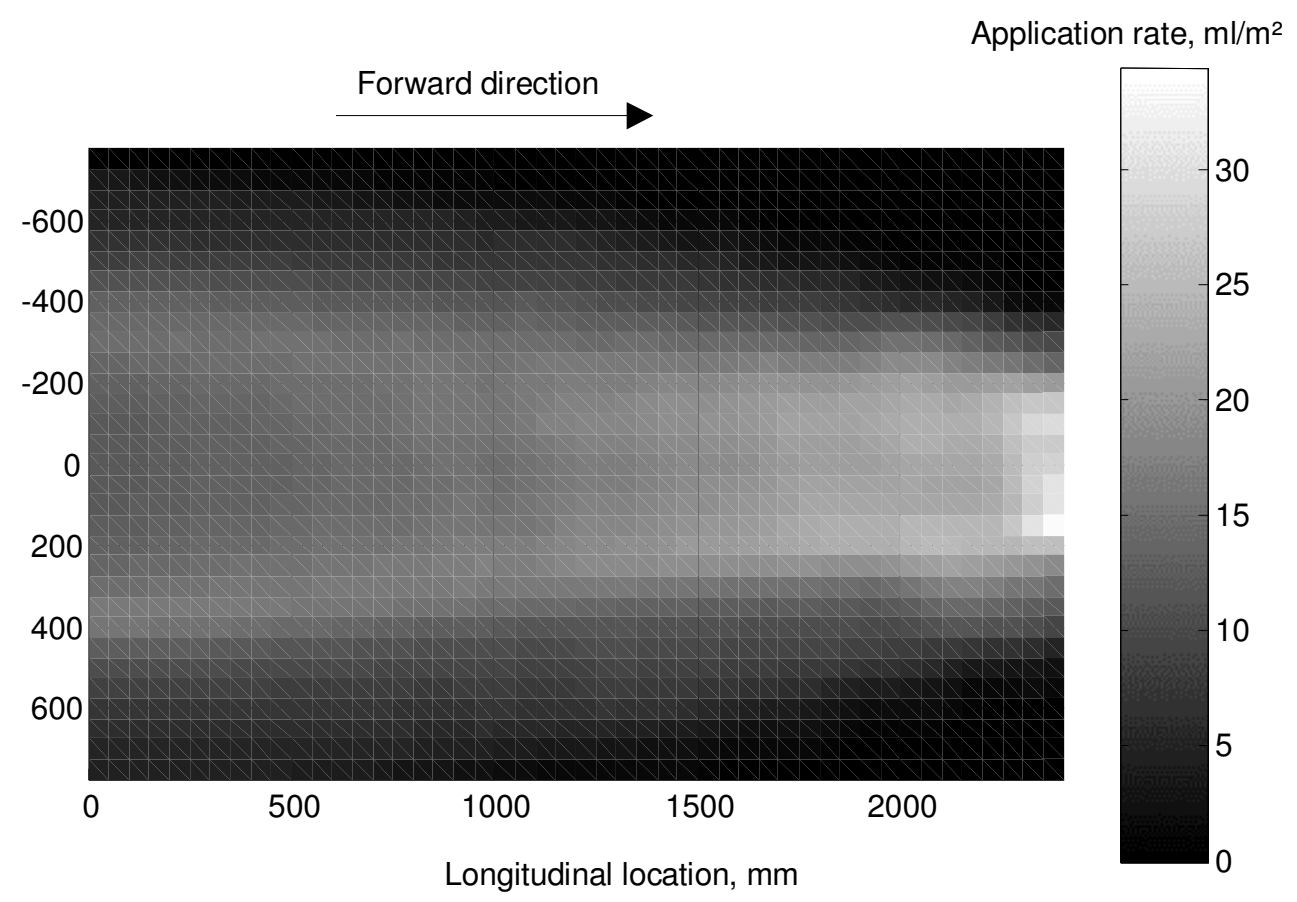

(c)

Fig. 14. Spray deposit distribution for a speed of $1 \mathrm{~m} / \mathrm{s}$ and a linear height variation from 700 to 300 mm within 2.5 metres; (a) Measured, (b) Modelled using static spray pattern, (c) Modelled using dynamic spray pattern 
Difference between modelled and measured application rates, $\mathrm{ml} / \mathrm{m}^{2}$

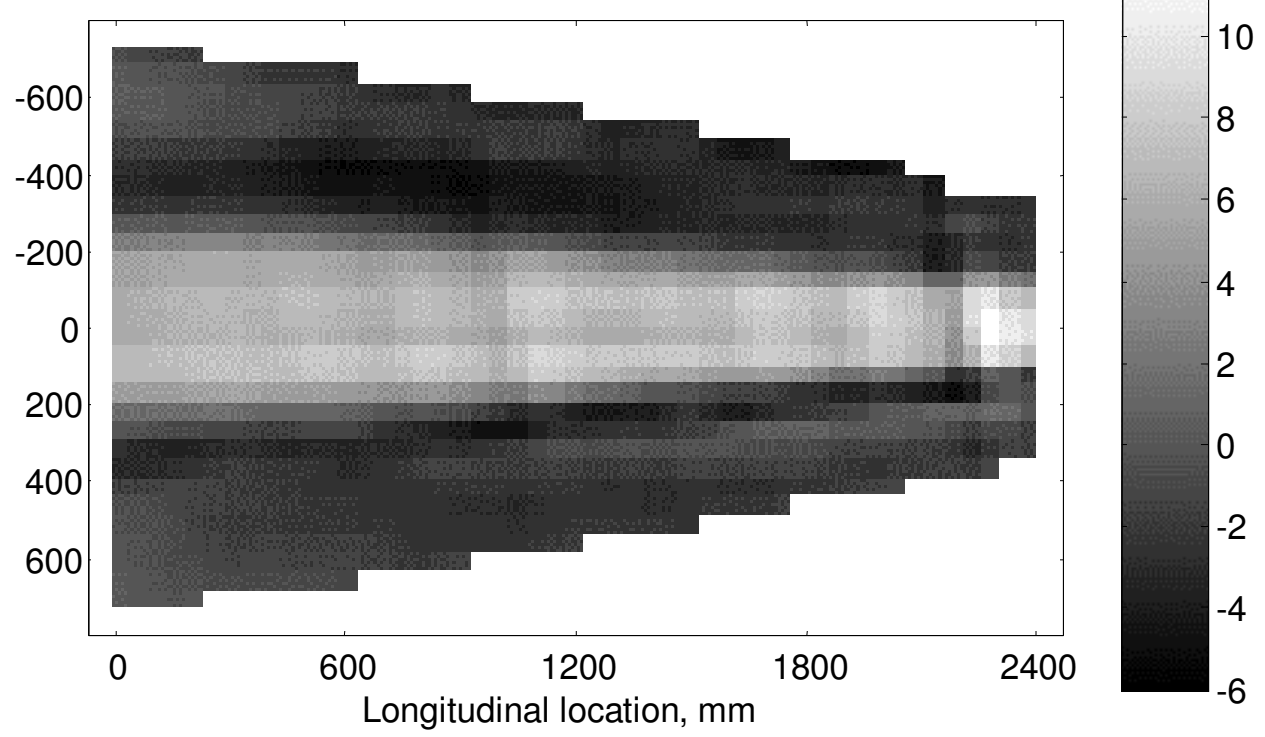

(a)

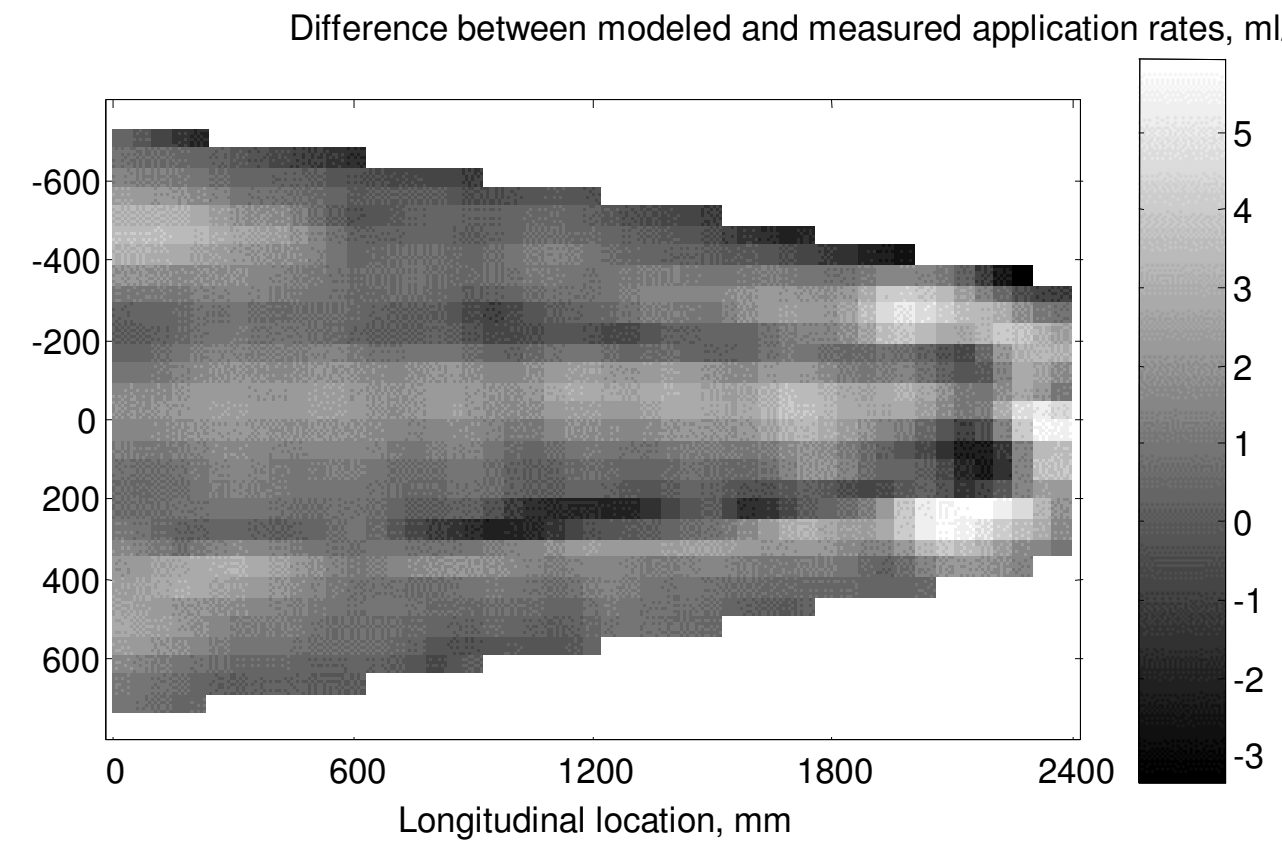

(b)

Fig. 15. Difference between measured and modelled spray deposit distribution for a speed of $1 \mathrm{~m} / \mathrm{s}$ and a linear height variation from 700 to $300 \mathrm{~mm}$ within 2.5 metres; (a) Modelled using static spray pattern, (b) Modelled using dynamic spray pattern 